\title{
Early stages of glass alteration in the coastal atmosphere
}

Teresa Palomar ${ }^{1,2^{*}}$, Daniel de la Fuente ${ }^{3}$, Manuel Morcillo ${ }^{3}$, Mónica Alvarez de Buergo ${ }^{4}$, Marcia Vilarigues $^{1,5}$

${ }^{1}$ Unidade de investigação VICARTE-Vidro e Cerâmica para as Artes, Campus de Caparica, FCTUNL, Quinta da Torre, 2829-516 Caparica, Portugal

${ }^{2}$ Instituto de Cerámica y Vidrio (ICV), Consejo Superior de Investigaciones Científicas (CSIC), c/ Kelsen 5, Campus de Cantoblanco, 28049 Madrid, Spain

${ }^{3}$ Centro Nacional de Investigaciones Metalúrgicas (CENIM), Consejo Superior de Investigaciones Científicas (CSIC), Avd. Gregorio del Amo 8, 28040 Madrid, Spain

${ }^{4}$ Instituto de Geociencias IGEO, Consejo Superior de Investigaciones Científicas y Universidad Complutense de Madrid, c/ Doctor Severo Ochoa 7, 28040 Madrid, Spain

${ }^{5}$ Departamento de Conservação e Restauro, Campus de Caparica, FCT-UNL, Quinta da Torre, 2829-516 Caparica, Portugal

*Corresponding author, e-mail: t.palomar@csic.es (T. Palomar)

\section{Abstract}

Urban and industrial atmospheres can produce several damages on glass façades and historical stained-glass windows; however, the effect of coastal atmosphere on them has been scarcely studied. This work presents the results of the exposure of soda-lime, potash-lime, and mixedalkali silicate glass to the coastal atmosphere in Cape Vilán (Galicia, Spain) at different distances to the coast (inland) during twelve months. Crystalline deposits were observed on all the samples, although their quantity depended on the meteorological conditions. The samples located nearest to the coast presented alteration layers, while those ones located farthest from the shore presented several isolated pits. Regarding the chemical composition, potashlime silicate glass, typical composition from medieval glass windows, was the most altered glass in contrast to soda-lime and mixed-alkali silicate glasses.

(C) 2018. This manuscript version is made available under the CC-BY-NC-ND 4.0 license. https://doi.org/10.1016/i.buildenv.2018.10.034 


\section{Graphical abstract:}

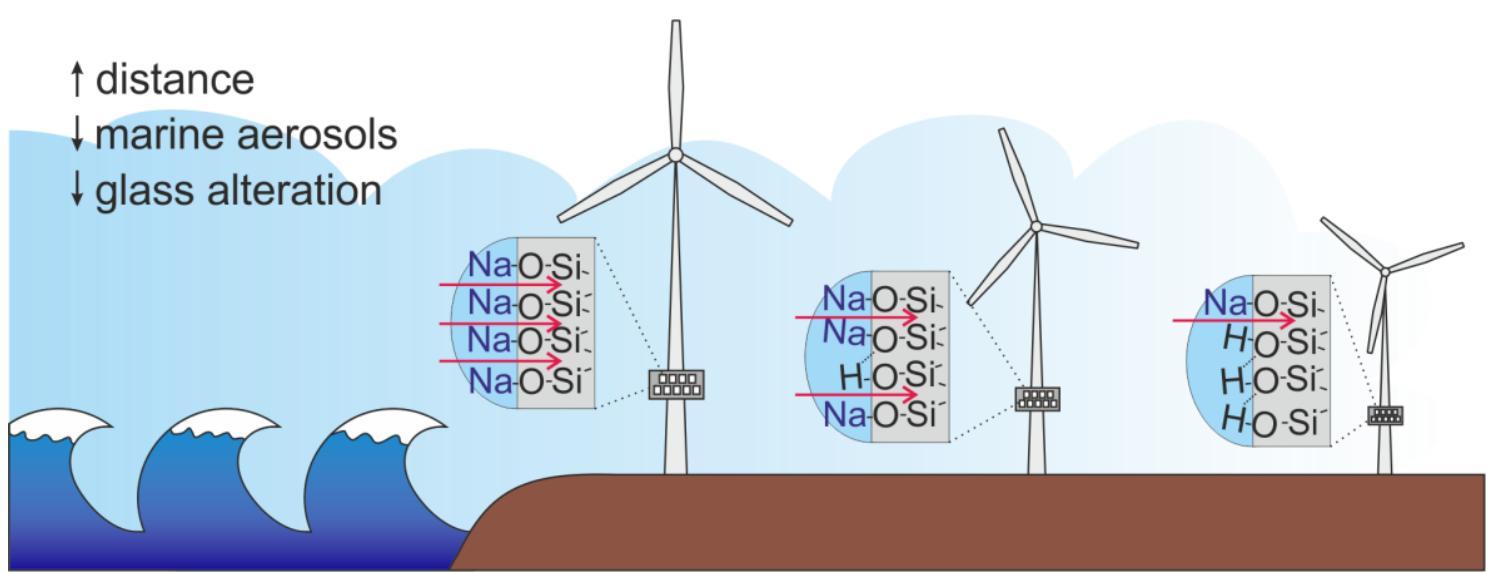

Keywords: Glass, degradation, marine aerosol, Atlantic coast.

\section{Highlights}

1. The glass alteration depended on the distance to the coast

2. The glasses exposed near the coast presented alteration layers on their surface

3. The glasses exposed far from the shore presented isolated pits

4. Potash-lime silicate glass was the most altered glass 


\section{Introduction}

Degradation of glass façades and historical stained-glass windows in atmospheric environment has been an important field of study in the last years since many of medieval windows present a poor state of conservation due to environmental factors [1-6]. The most common weathering pathologies are dust accumulation, pits, and crusts. These pathologies decrease the glass transparency, diminishing the artistic value of the stained-glass windows [2-5, 7-12].

Soiling is the most common alteration pathology in glasses and it concerns the deposit of soot particles and salts over its surface. The nature of these deposits depends on the type of atmosphere to which the glasses are exposed (urban, industrial, rural...), although insoluble mineral dust and the soluble inorganic species $\mathrm{SO}_{4}{ }^{2-}, \mathrm{NO}_{3}{ }^{-}, \mathrm{Ca}^{2+}, \mathrm{Na}^{+}$and $\mathrm{Cl}^{-}$are the most common ones [7-9]. Surface deposits produce the increase of the surface roughness and the hygroscopicity [7]. Water, both rain and condensation, is the main degradation agent because it produces the lixiviation of alkaline and alkaline-earth ions from the glass matrix and the hydrolytic attack of the siloxane bonds $[2,3,5,10,11]$. As a result of this attack, pits and alteration layers can be produced.

Environmental pollution produces also a very intense effect on glass. Urban environments induce more intense soiling and alteration pathologies than sub-urban areas due to the higher pollution in the former areas $[3,5,12]$. Moreover, the atmospheric gases $\left(\mathrm{CO}_{2}, \mathrm{SO}_{2}, \mathrm{NO}_{2}\right)$, solubilized in rainwater, can react with the alkaline and alkaline-earths ions $\left(\mathrm{Na}^{+}, \mathrm{K}^{+}, \mathrm{Ca}^{2+}\right)$ leached from the glass to form crystalline deposits [4]. The accumulation of these deposits on the glass surface can form thick crusts of carbonates or sulfates.

One of the least assessed environments is the coastal atmosphere. In this environment, the content of marine aerosols is high and they can induce a severe damage on different materials, such as metal or stone [13-19]. Nevertheless few studies on glass alteration have been carried out. In the frame of the "International Co-operative Programme on Effects on Materials including Historic and Cultural Monuments" (ICP Materials), several glass samples were spread around Europe in different atmospheres (industrial, urban, rural) [20]. The samples exposed in Athens, in a coastal environment, presented a more intense alteration process in comparison with other European cities with inland atmospheres [12]. Furthermore, some glasses exposed in Galicia (Spain) showed the formation of several crystalline phases (chlorides, carbonates...) and, even, alteration layers after being exposed during three months in a coastal atmosphere [21]. The fast alteration of these modern glasses proves the aggressiveness of the coastal atmospheres. High concentration of marine aerosols can be detected as far as $\sim 20 \mathrm{~km}$ from 
the coast (inland) depending on the local geography [22, 23]. For this reason, historical stained-glass windows without protection and glass façades exposed near the shore could be threatened.

The aim of this study is to determine the alteration mechanism of three type of glasses (sodalime, potash-lime, and mixed-alkali silicate glasses) located at different distances to the shore. The samples were exposed unsheltered from rain during twelve months to characterize the real impact of a coastal atmosphere in the glass degradation. This research will be especially useful to evaluate the conservation strategies of coastal stained-glass windows and glass façades.

\section{Experimental}

\subsection{Glass Samples}

Three different glasses were formulated following the composition of the most common glasses from stained-glass windows and glass façades from different historical periods: sodalime silicate (NCV), mixed-alkali silicate (MCV) and potash-lime silicate glasses (KCV) (Table 1). They were melted in the laboratory and blown into the form of a roundel with the same procedure than the historical production of crown window glass [24]. Ten samples of each glass were cut in slices of $(1 \times 1 \times 0.2) \mathrm{cm}^{3}$.

Table 1. Chemical composition of soda-lime silicate (NCV), mixed-alkali silicate (MCV) and potash-lime silicate (KCV) glasses analyzed by Particle Induced X-ray Spectrometry (PIXE).

\begin{tabular}{|c|c|c|c|c|c|c|c|c|c|c|c|c|c|c|c|}
\hline & \multicolumn{15}{|c|}{ Chemical composition (wt. \%) } \\
\hline & $\mathrm{Na}_{2} \mathrm{O}$ & $\mathrm{MgO}$ & $\mathrm{Al}_{2} \mathrm{O}_{3}$ & $\mathrm{SiO}_{2}$ & $\mathrm{P}_{2} \mathrm{O}_{5}$ & $\mathrm{SO} 3$ & $\mathrm{Cl}^{-}$ & $\mathrm{K}_{2} \mathrm{O}$ & $\mathrm{CaO}$ & $\mathrm{TiO}_{2} \mathrm{Cr}_{2} \mathrm{O}$ & $\mathrm{D}_{3} \mathrm{MnO}$ & $\mathrm{O} \mathrm{Fe}_{2} \mathrm{O}_{3}$ & $\mathrm{CuO}$ & $\mathrm{ZnO} \mathrm{SnO}_{2}$ & $\mathrm{PbO}$ \\
\hline NCV & 16.91 & 1.77 & 3.15 & 66.12 & 0.02 & 0.03 & 0.01 & 2.86 & 7.30 & $0.03-$ & 0.09 & 0.27 & - & 1.150 .28 & - \\
\hline MCV & 11.70 & 3.43 & 6.81 & 62.97 & 0.12 & & 0.01 & 4.72 & 8.83 & $0.12-$ & 0.38 & 0.55 & - & 0.38 & \\
\hline KCV & 0.10 & 1.96 & 4.16 & 57.14 & 1.76 & 0.01 & & 17.56 & 616.64 & 40.060 .01 & $1-$ & 0.12 & 0.01 & 0.45 & 0.01 \\
\hline
\end{tabular}

\subsection{Corrosion tests}

The samples were exposed in the Cape Vilán wind farm (Galicia, Spain) for periods of 3, 6, 9 and 12 months. They were placed in a vertical position unsheltered from the rain in three different corrosion stations located at different distances from the Atlantic shore $(332,710$ and $1250 \mathrm{~m}$ ). The deposition rate of atmospheric chloride ions (salinity) was measured by the Wet Candle Method [25] and depended on the distance from the corrosion stations to the shore (Table 2). Frequent heavy rainfall and high relative humidity levels were recorded by the AEMET (Spanish Meteorological Agency) at the test site (Table 2 and Table 3), which confirmed 
the prolonged times of wetness on the glass surface. The atmospheric $\mathrm{SO}_{2}$ content was negligible [26]. The Corrosion station 1 disappeared after 12 months of exposure due to strong winds in the area.

Table 2. Total precipitation, average wind speed and deposition rate of atmospheric chloride ions measured in the corrosion stations during the exposure periods with the Wet Candle Method [25].

\begin{tabular}{llllllll}
\hline Exposure period & $\begin{array}{l}\text { Total } \\
(\mathrm{mm})\end{array}$ & precipitation & $\begin{array}{l}\text { Average } \\
(\mathrm{km} / \mathrm{h})\end{array}$ & wind & speed & \multicolumn{4}{c}{ Corrosion station $/ \mathrm{Cl}^{-}\left(\mathrm{mg} / \mathrm{m}^{2} \cdot\right.$ day) } \\
& 109.0 & 19.0 & 1 & 699.8 & 178.2 & 36.1 \\
\hline $07 / 16-10 / 16$ & 16 & 20.0 & 900.9 & 291.6 & 57.2 \\
$10 / 16-01 / 17$ & 256.9 & 28.3 & 2214.1 & 620.7 & 73.8 \\
$01 / 17-04 / 17$ & 313.6 & 20.0 & - & 288.1 & 28.9 \\
$04 / 17-07 / 17$ & 95.2 & & & & 2 & 3 \\
\hline
\end{tabular}

- Not available

Table 3. Meteorological factors during the exposure in Cape Vilán wind farm (Galicia, Spain).

\begin{tabular}{ll}
\hline Climate parameters & Average value \\
\hline Prevailing wind & Northeast wind \\
Temperature & $14.6 \pm 3.0 \circ \mathrm{O}$ \\
Humidity & $85 \pm 4 \%$ \\
Days per month with precipitation $>0.1 \mathrm{~mm}$ & $13 \pm 4$ days \\
Days per month with precipitation $>1 \mathrm{~mm}$ & $8 \pm 5$ days \\
Total monthly precipitation & $61.6 \pm 49.9 \mathrm{~mm}$ \\
\hline
\end{tabular}

\subsection{Characterization techniques}

Glass samples were characterized by the following techniques: Optical microscopy (OM), Fourier Transform Infrared Spectroscopy in Attenuated Total Reflectance (FTIR-ATR) and Optical surface roughness (OSR). The static contact angle (water drop-glass surface) was also measured.

OM was carried out by a Zeiss Axioplan 2 microscope equipped with the objectives $\times 5, \times 20$, $\times 50$ and $\times 100$ in reflective light mode with bright field. The images were taken with a Nikon digital DXM1200F camera coupled to the microscope.

Fourier Transform Infrared spectroscopy (FTIR) was carried out with a 4300 Handheld FTIR spectrometer of Agilent Technologies. The measurements were obtained in Attenuated Total Reflection (FTIR-ATR) mode with a spectral range from 4000 to $650 \mathrm{~cm}^{-1}$ and a spectral resolution of $4 \mathrm{~cm}^{-1}$. Each spectrum was the product of 32 internal scans. In order to compare spectra, the horizontal baseline was corrected with the baseline subtraction in the range 3800 $4000 \mathrm{~cm}^{-1}$ and, then, spectra were normalized to the maximum peak with the software Spectragryph version 1.2.6. 
The surface micro-roughness was measured with an optical roughness meter TRACEIT from Innowep $\mathrm{GmbH}$. 3D topographical maps ( $5 \times 5 \mathrm{~mm}$ area, and height in $\mu \mathrm{m}$ ) were carried out with a resolution of $2.5 \mu \mathrm{m}$ (in $\mathrm{X}, \mathrm{Y}$ and $\mathrm{Z}$ axes). To compare the glass surfaces, three roughness maps $(2 \times 2 \mathrm{~mm})$ were measured on each sample, they were flattened and the arithmetic average roughness, Ra [27], was calculated with the software Gwyddion version 2.32. The average of Ra was calculated for each sample.

The static contact angle (water drop-glass surface) was determined with a Drop Shape Analyzer Phoenix 300 Seo from Surface Electro Optics [28]. The diameter of the needle was $0.483 \mathrm{~mm}$ (interior) and $0.711 \mathrm{~mm}$ (exterior).

\section{Results and Discussion}

\subsection{Surface pathologies}

All glasses exposed to the environmental conditions of Cape Vilán (Spain) presented alteration pathologies, even after 3 months of exposure. The most common pathology was the presence of surface crystals. They were both deposited from environmental particles such as aerosols and dust, or formed by the alteration of the glass surface. The number of deposits located was related to the atmospheric condition during the days before the collection. If samples were collected after a drought period, deposits were spread on the surface; however, if the glasses were collected after a rainy period, some isolated deposits were observed on the glass surface because rainwater washed the surface.

The inland distance to the shore affected the deposits composition. Large cubic crystalline salts attributed to $\mathrm{NaCl}$ crystals were observed on the samples from the Corrosion station 1 , the nearest to the shore (Fig. 1 a). In general, surface deposits favored the retention of water content on the surface, which was observed by optical microscopy as dark or iridescent haloes around the deposits (Fig. 1 b). This water can stay on the glass surface for long periods of time favoring the local alteration of the glass in the long term. 

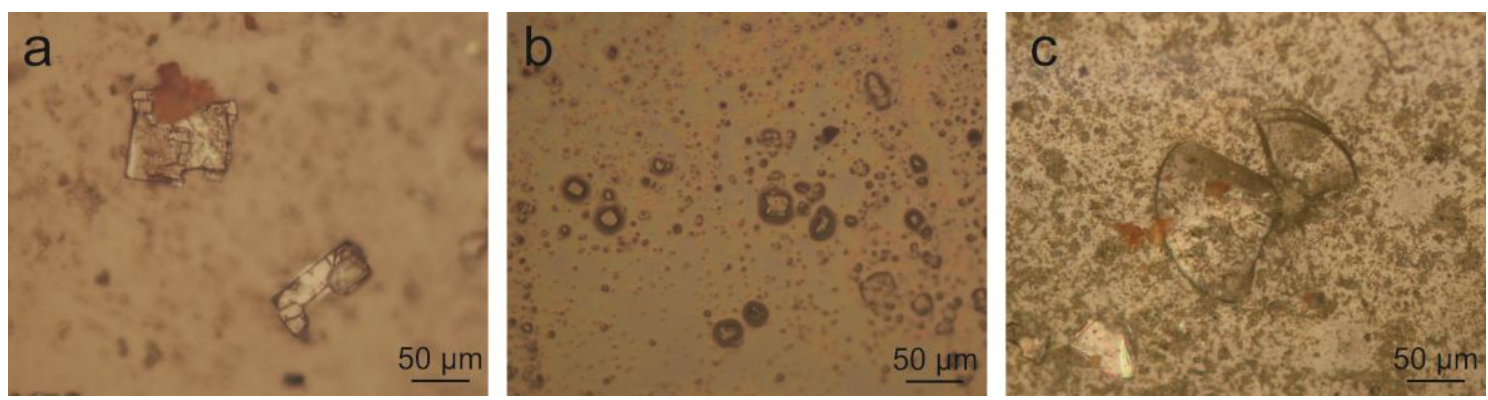

Fig. 1. OM images of the a) deposits on the sample KCV3 after 3 months, b) deposits on the sample MCV1 after 6 months, c) mechanical impact on the sample KCV1 after 6 months.

Some samples presented also mechanical impacts on their surface due to the collision of soil particles transported by the wind at high speed $[29,30]$. The mechanical impact created conchoidal fractures in the impact point (Fig. $1 \mathrm{c}$ ), whose dimensions depended on size, form, composition, hardness, impact angle and velocity of the soil particles [30].

Regarding the chemical alteration of the glass, both alteration layers and pits were observed on the surface as result of their exposure to the coastal atmosphere. Alteration layers were observed in soda-lime silicate and mixed-alkali silicate glasses exposed during 9 and 12 months in the Corrosion stations 1 and 2. This alteration layer was observed by optical microscopy as a whitish layer (Fig. 2 a). This layer is very fragile and uses to appear fissured or with scratching marks due to the sample manipulation. Potash-lime silicate glasses showed interference colors, characteristic of the initial stage of the alteration layer, after just 3 months in the three corrosion stations (Fig. 2 b). After 6 and 9 months, the glasses exposed in the Corrosion station 1 presented also whitish areas, which were related to the separation of the most external alteration layers (Fig. 2 c).
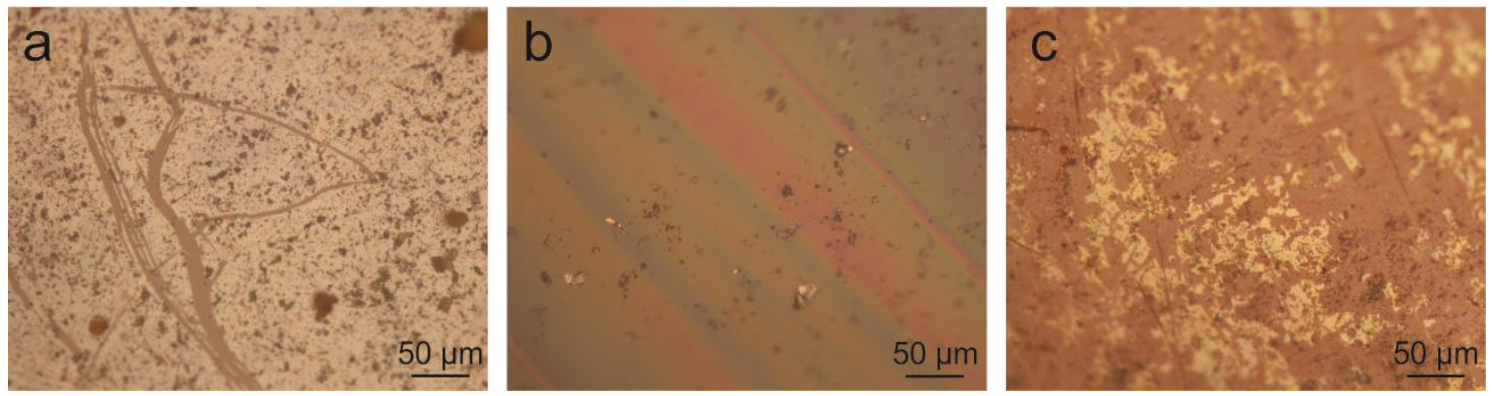

Fig. 2. OM images of the a) alteration layer on the sample NCV1 after 9 months, b) interference colors on the sample KCV1 after 3 months, c) alteration layer on the sample KCV1 after 9 months. Scratching marks are due to sample manipulation.

Pits in an initial state of alteration were also detected on the glasses from the Corrosion station 3 after 9 and 12 months of exposure, independently of the chemical composition of the sample. The majority of the pits were formed by a rounded deposit surrounded by an alteration layer, with iridescent or whitish color (Fig. 3 a). The iridescence observed around the 
pits is an optical phenomenon related to the formation of the alteration layer; however, the whitish color is due to the separation of the thin alteration layer. The latter is very fragile and it appears frequently fractured (Figs. 3 b and c).
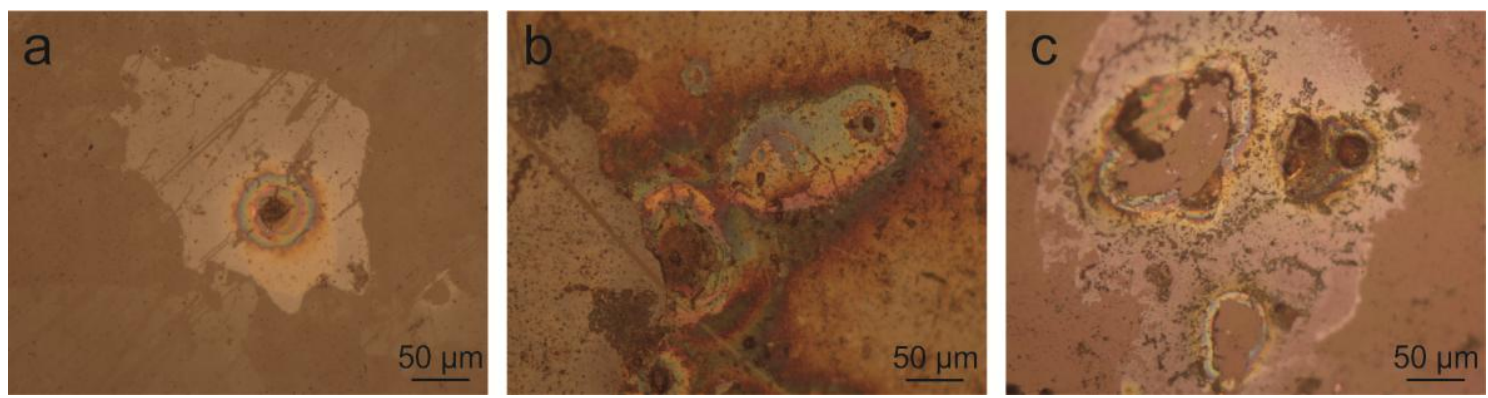

Fig. 3. OM images of the pits in the sample a) NCV3 after 12 months, b) MCV3 after 12 months, c) KCV3 after 9 months.

Some samples presented also insect eggs on their surface (Fig. 4). The eggs were white round spheres, but under the microscope light they look dark, and some of them appeared hatched. It is interesting that neither pits nor other pathologies related to water retention were observed under them; either because the eggs were placed on the glasses a short time before the glass collection or because the eggshells were hydrophobic [31].

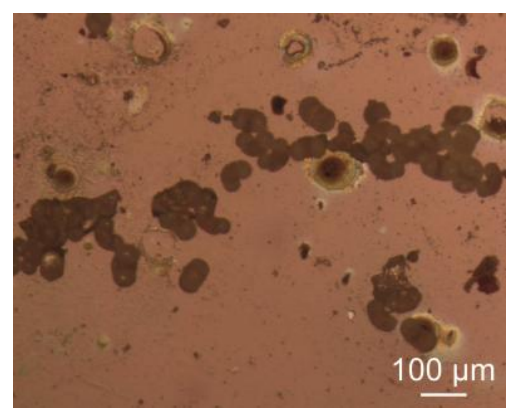

Fig. 4. OM image of insect eggs on the KCV3 sample.

\subsection{Surface roughness and wetting properties}

The surface of the blown glass was not as flat as industrial or polished glass because it was made by a traditional elaboration process (Section 2.1.). These irregularities, together with surface deposits, influenced the surface topography.

Most of the samples presented a similar roughness $(\mathrm{Ra}=4-8 \mu \mathrm{m})$ (Table 4, Fig. 5 a), which was attributed to the glass surface topography instead of the corrosion process. The glasses exposed during three months in the Corrosion station 3 were the roughest ones ( $\mathrm{Ra} \approx 11 \mu \mathrm{m}$ ) due to the presence of large deposits on them (Fig. 5 b); and some glasses presented Ra $<2$ (Table 4) because they showed a homogeneous clean surface (Fig. $5 \mathrm{c}$ ), which could be related to a punctual cleaning of the surface (environmental, manual) or to the good wetting between 
water and glass surface (Table 5) [21]. The scratching marks due to manipulation and/or losses of alteration layers (Fig. 2 a and 3 c) have a depth of few micrometers and they were not observed in the roughness maps.

The contact angle between water drops and glass surface before the exposure is similar in the three glasses independently from the glass composition (Table 5), because the three glasses were fire polished (Section 2.1). During their manufacture, volatile ions, such as alkaline ions, were slightly evaporated from the surface creating a nanometric layer enriched in $\mathrm{SiO}_{2}$ similar in the three glasses $[32,33]$. This layer also stabilizes the surface because alkaline ions, the most vulnerable ones, were protected by the silica lattice. After the exposure, the contact angle between water drops and glass surface increased their value possibly due to the exchange of $\mathrm{H}^{+}$-ions from glass surface and $\mathrm{Na}^{+}$-ions from marine aerosols (Table 5). In general, the presence of deposits on the surface did not influence the contact angle because they are soluble in the water drop.

Table 4. Average roughness (OSR) of the glass surface $(2 \times 2 \mathrm{~mm})$ in function of the time and the distance to the shore. * Analyzed area: $1 \mathrm{~mm}^{2}$.

\begin{tabular}{llrrr}
\cline { 2 - 4 } & \multicolumn{4}{l}{ Average Ra $(\mu \mathrm{m})$} \\
\hline Samples & Time (months) & Station 1 & Station 2 & \multicolumn{1}{c}{ Station 3 } \\
\hline NCV & 0 & $5.3 \pm 0.3$ & $5.4 \pm 1.4$ & $7.6 \pm 0.5$ \\
& 3 & $5.3 \pm 0.4$ & $1.6 \pm 0.1$ & $11.4 \pm 0.4$ \\
& 6 & $5.5 \pm 2.3$ & $6.5 \pm 1.5$ & $3.5 \pm 0.6$ \\
& 9 & $7.0 \pm 1.6$ & $3.8 \pm 0.9$ & $7.6 \pm 2.6$ \\
& 12 & - & $7.4 \pm 1.9^{*}$ & $1.1 \pm 0.1$ \\
KCV & 0 & $3.4 \pm 0.3$ & $4.7 \pm 0.9$ & $6.7 \pm 0.6$ \\
& 3 & $2.1 \pm 0.7$ & $5.6 \pm 1.6$ & $11.1 \pm 2.6$ \\
& 6 & $3.9 \pm 1.2$ & $3.6 \pm 1.5$ & $4.1 \pm 0.8$ \\
& 9 & $2.3 \pm 0.4$ & $3.4 \pm 0.8$ & $4.2 \pm 1.0$ \\
MCV & 12 & - & $6.0 \pm 2.9^{*}$ & $7.3 \pm 0.6$ \\
& 0 & $5.9 \pm 0.9$ & $5.4 \pm 1.3$ & $5.9 \pm 1.1$ \\
& 3 & $3.4 \pm 1.3$ & $7.9 \pm 0.7$ & $11.1 \pm 1.6$ \\
& 6 & $4.0 \pm 2.0$ & $6.8 \pm 2.6$ & $4.7 \pm 3.7$ \\
& 9 & $4.3 \pm 1.3$ & $6.0 \pm 1.9$ & $4.3 \pm 0.8$ \\
& 12 & - & $6.5 \pm 2.5^{*}$ & $7.7 \pm 1.3$ \\
\hline
\end{tabular}

- Not available 

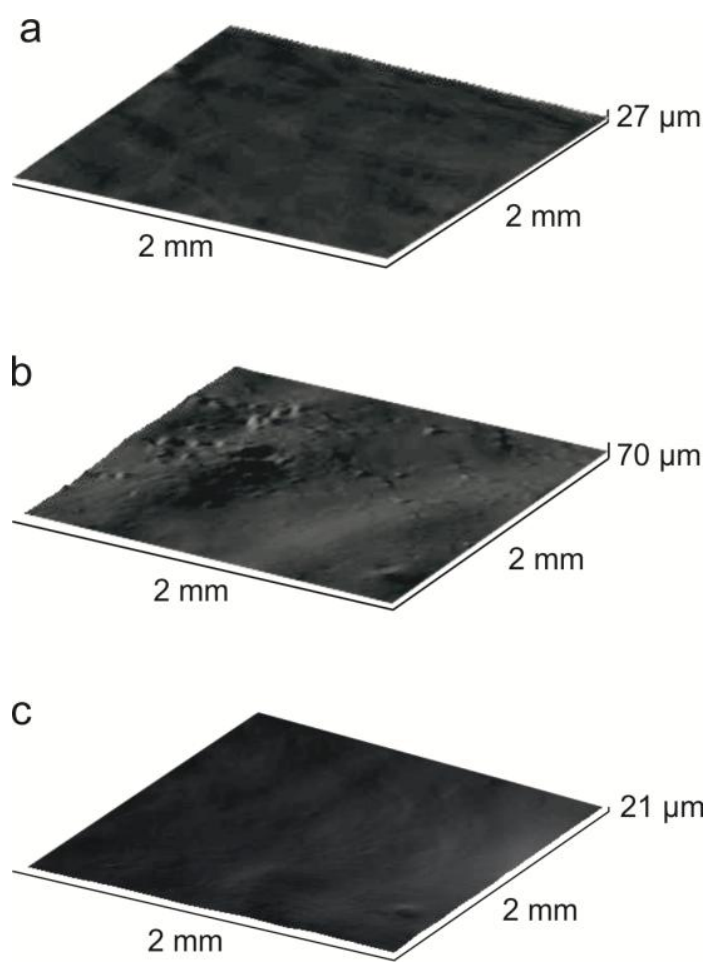

Fig. 5. Roughness maps from the surface of the samples a) MCV1, b) KCV3, c) NCV3, after 3 months.

Table 5. Average of contact angle values (in degrees) and standard deviation measured for drops of distilled water on the glass surfaces before and after the exposure.

\begin{tabular}{|c|c|c|c|c|c|}
\hline & \multicolumn{5}{|l|}{ Contact angle $\left({ }^{\circ}\right)$} \\
\hline & \multirow[t]{2}{*}{ Before exposure } & \multicolumn{2}{|c|}{ Station 1 (9 months) } & \multicolumn{2}{|c|}{ Station 3 (9 months) } \\
\hline & & With deposits & Without deposits & With deposits & Without deposits \\
\hline NCV & 26.8 & 59.9 & 60.2 & 40.2 & 38.6 \\
\hline KCV & 29.6 & 42.7 & 48.5 & 58.1 & 49.4 \\
\hline MCV & 29.6 & 51.3 & 68.6 & 57.5 & 46.6 \\
\hline
\end{tabular}

\subsection{Chemical alteration}

The evolution of the surface alteration in the coastal atmosphere was characterized by FTIRATR. The spectra of soda-lime silicate glasses were similar in the three corrosion stations during the 12 months of exposure (Figs. 6 a, b and c). The modification of the infrared bands was almost negligible; however, the sample NCV1 after 9 months presented a low increase in the band of the asymmetric stretching of the Si-O-Si (Fig. 6 a). This increase can be related to the formation of the silica gel layer on the surface [34]. The band attributed to the bending of the molecular water adsorbed on the surface $\left(\delta_{\mathrm{H} 2 \mathrm{O}}\right)$ was also detected in some samples (Fig. 6 a). 

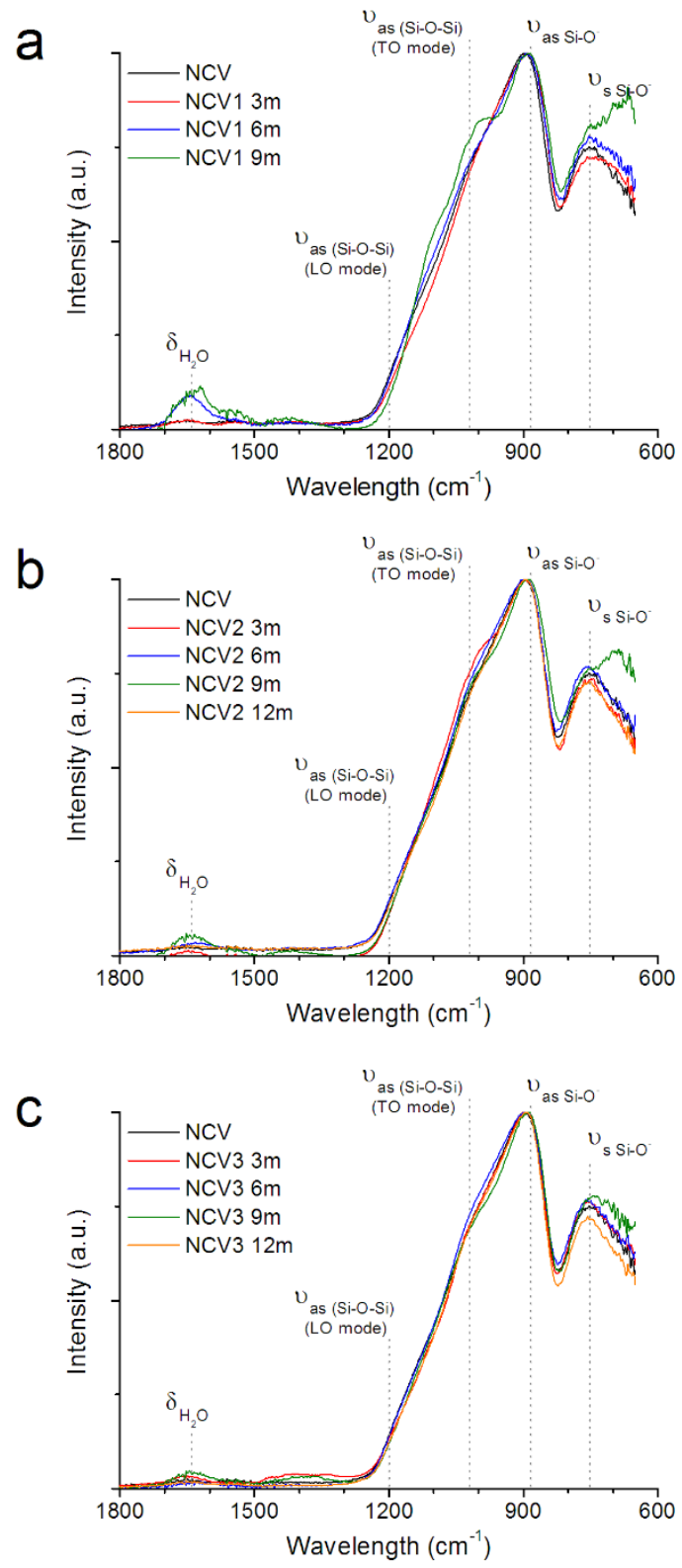

Fig. 6. FTIR-ATR spectra of soda-lime silicate glasses from the a) Corrosion station 1, b) Corrosion station 2, and c) Corrosion station 3.

Mixed-alkali silicate glasses showed a similar behavior than soda-lime glasses (Figs. 7 a, b and c). Glass samples were almost stable in the Corrosion stations 2 and 3; however, the samples exposed in the Corrosion station 1, the nearest to the shore, presented the progressive formation of the alteration layer on the glass surface (Fig. 7 a). The band attributed to the asymmetrical stretching of the siloxane bonds $\left(U_{\text {as }(\text { Si-O-si) }} \sim 1010 \mathrm{~cm}^{-1}\right)$ increased its height after the glass being exposed 6 and 9 months as result to the formation of the alteration layer (Fig. 7 a). It was observed also the bending band of the molecular water adsorbed on the glass surface (Figs. 7 a, b and c). 

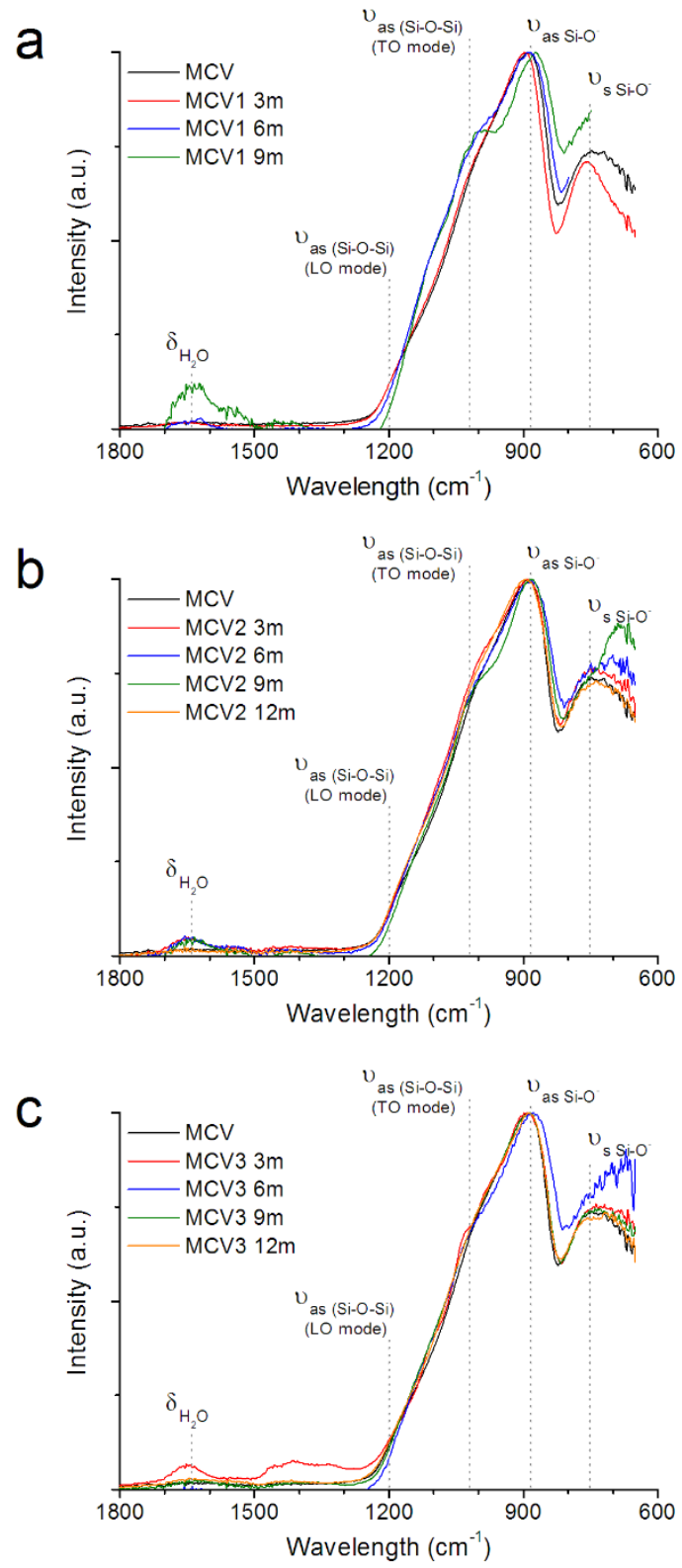

Fig. 7. FTIR-ATR spectra of mixed-alkali silicate glasses from the a) Corrosion station 1, b) Corrosion station 2, and c) Corrosion station 3.

Contrary to soda-lime and mixed-alkali silicate glasses, potash-lime silicate glass was the most unstable glass in the Cabo Vilano conditions because all the samples, even after 3 months of exposure, were altered (Figs. 8 a, b and c). It was observed the progressive increase in the IR bands related to the asymmetric stretching of the siloxane bond $\left(\sim 1010\right.$ and $\left.\sim 1200 \mathrm{~cm}^{-1}\right)$ and a decrease in the stretching band of the silanol groups $\left(\sim 870 \mathrm{~cm}^{-1}\right)$ (Figs. $8 \mathrm{a}, \mathrm{b}$ and c). Hydration water was also detected in all the samples (Figs. 8 a, b and c). 

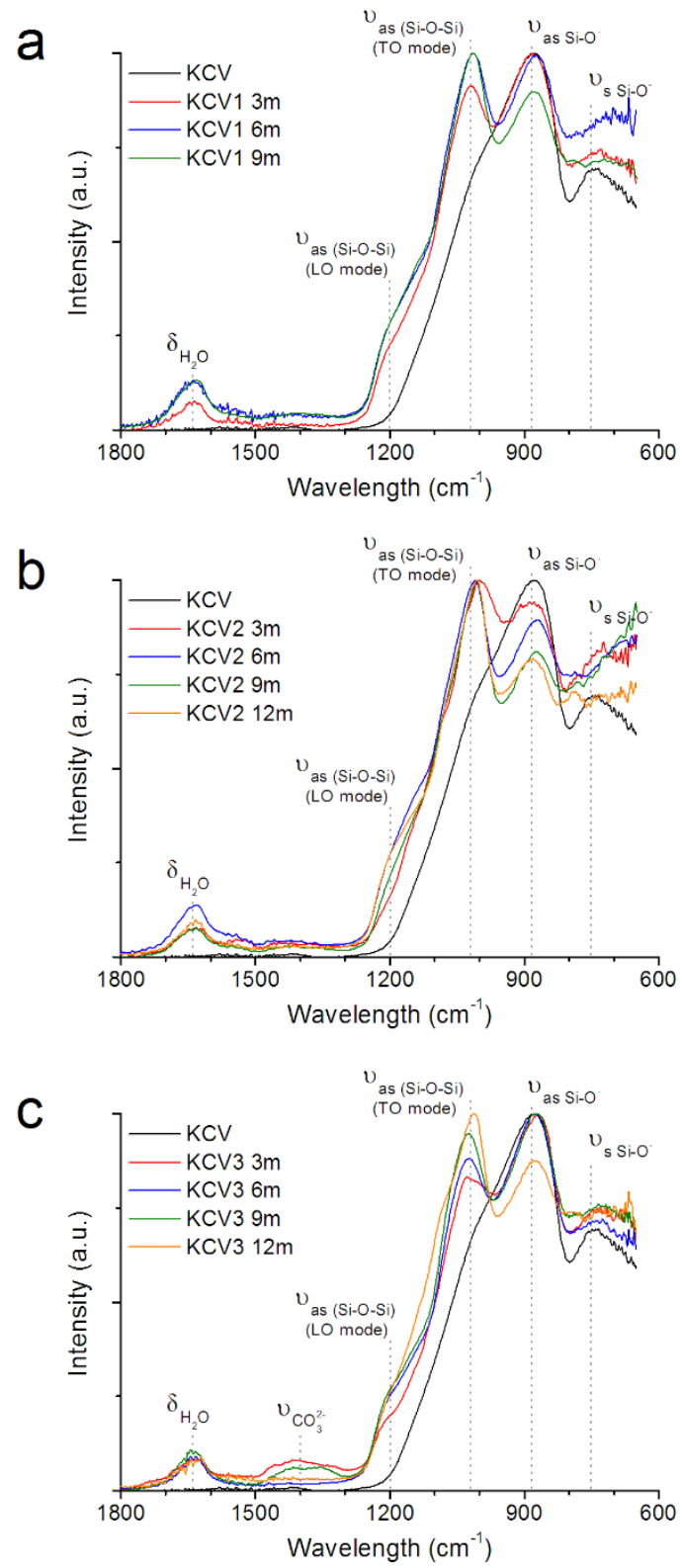

Fig. 8. FTIR-ATR spectra of potash-lime silicate glasses from the a) Corrosion station 1, b) Corrosion station 2, and c) Corrosion station 3.

Some spectra presented the bands attributed to the carbonate groups, mainly in the samples from the Corrosion station 3 (Fig. $8 \mathrm{c}$ ). The carbonates could be environmental aerosols or formed as result of the reaction between the leached ions from the glass with the environmental $\mathrm{CO}_{2}$. The most probable compound is $\mathrm{CaCO}_{3}$, which is the most stable deposit and with less solubility according to the evolution of the crystalline phases on glass alteration [21]. 


\section{Discussion}

\subsection{Influence of the environment}

The corrosion stations were located in the Cape Vilán wind farm, in the west coast of Galicia (Spain), in the "Costa da Morte" ("Coast of Death"). This area presents a temperate climate with dry and temperate summer ( $\mathrm{Csb}$ ) according to the Köppen-Geiger climate classification $[35,36]$ and a West European Maritime Climate according to the Climatic regions of the Iberian Peninsula [37]. This region is characterized by a warm temperate climate with dry summers ( $\mathrm{T}$ (temperature) $)_{\max }<22 \stackrel{\circ}{\circ} \mathrm{C}, \mathrm{T}_{\text {mean }}>10 \stackrel{\circ}{ } \mathrm{C}$ during more than 4 months per year, $P$ (precipitations) $)_{\text {min_summer }}<P_{\text {min_winter, }} P_{\text {max_winter }}>3 P_{\text {min_summer, }}$ and $P_{\text {min_summer }}<40 \mathrm{~mm}$ ) [38].

Marine atmosphere predominates at a maximum distance of $\sim 20 \mathrm{~km}$ from the coast $[22,23]$, as in the Cape Vilán wind farm $(<1.5 \mathrm{~km})$. The prevailing wind of the area is the northeast wind which brings marine aerosols from the Arneliña inlet, in the Atlantic Ocean. It was observed that higher wind speed, faster deposition rate of atmospheric chloride ions on the corrosion stations (Table 2). The coarse particles from marine aerosols are mainly composed by sea salt, predominantly sodium and chlorine ions $[39,40]$. The main route of $\mathrm{Cl}^{-}$- and $\mathrm{Na}^{+}$-ions deposition is by wet deposition [23] and they can form $\mathrm{NaCl}$ crystals on the glass surface (Fig. 1 a).

During the exposure period, the temperature was around $15{ }^{\circ} \mathrm{C}$ and the relative humidity was very high ( $85 \%)$ (Table 3). Under these environmental conditions, glass surfaces were covered by few monolayers of liquid water [41]. This water can induce the hydrolytic attack (Reaction 1) and the dealkalization of the glass surface (Reaction 2). The silanol bonds formed as result of these reactions can polymerize between them to form a porous layer enriched in $\mathrm{SiO}_{2}$ (Reaction 1), which is commonly called silica gel layer [42].

$$
\begin{gathered}
\equiv \mathrm{Si}-\mathrm{O}-\mathrm{Si} \equiv+\mathrm{H}_{2} \mathrm{O} \rightleftharpoons 2 \equiv \mathrm{Si}-\mathrm{O}-\mathrm{H} \\
\equiv \mathrm{Si}-\mathrm{O}-\mathrm{M}+\mathrm{H}_{3} \mathrm{O}^{+} \rightarrow \equiv \mathrm{Si}-\mathrm{O}-\mathrm{H}+\mathrm{M}^{+}+\mathrm{H}_{2} \mathrm{O}
\end{gathered}
$$

This silica gel layer presents a more open structure than bulk glass and permits the diffusion of water molecules and other chemical species through it [43, 44]. Both hydrolysis and dealkalinization can occur simultaneously in the bulk glass below the silica gel layer, continuing the dealkalization process and increasing the thickness of the alteration layer.

The dealkalization reaction releases alkaline and hydroxyl ions to the medium (Reaction 2). If the concentration of these basic ions is high $(\mathrm{pH}>9)$, they can break the oxygen bridge bonds 
inducing the irreversible disruption of glass network (Reaction 3). The accumulation of negative charges in the alteration layer also increases the repulsion forces which tend to open the glass network, accelerating the alteration process $[45,46]$. Rainwater can wash the leached ions (alkaline, alkaline-earth and hydroxyl ions) from the glass surface. The removal of hydroxyl ions favors the maintenance of a neutral pH in the surface glass, which prevents the basic corrosion mechanism (Reaction 3 ).

$$
\equiv \mathrm{Si}-\mathrm{O}-\mathrm{Si} \equiv+\mathrm{OH}^{-} \rightarrow \equiv \mathrm{Si}-\mathrm{OH}+\equiv \mathrm{Si}-\mathrm{O}^{-}
$$

Precipitations during the exposure period were recurrent, mainly during the winter (Table 2). Around 13 days per month rained in Cape Vilán, 8 days/month rained moderately, and they presented an average of $61.6 \mathrm{~mm} /$ month (Table 3 ). This intermittent rain produced a degradation mechanism alternating between active and static state. During the rainy period, the glass surface was washed and the basic ions and deposits were removed $[5,11]$. However, when the rain stopped, a thick layer of water stayed on the glass surface for a long time due to the high environmental humidity. This water can cause a hydrolytic attack favoring the formation of the alteration layer (Reaction 1 and 2). This water can also dissolve aerosols and atmospheric gases, which can react with the leached ions from the glass to form deposits when water evaporates [4]. The most common deposits in the coastal atmosphere, according to their Gibbs free energy of formation and solubility, are $\mathrm{CaCO}_{3}, \mathrm{Na}_{2} \mathrm{CO}_{3}$ and $\mathrm{NaCl}$ [21]. These deposits can retain water on the glass which can induce punctual alterations (Fig. 1 b) [10, 47]. The number of deposits on the surface depended on the atmospheric condition before and during the collection. If rainwater washed the surface, fewer deposits were observed on it.

$\mathrm{NaCl}$ aerosols also induce the increase of the hygroscopicity on the glass surface. The hygroscopic behavior of single crystals of $\mathrm{NaCl}$ has a well-defined deliquescence point at $~ 76 \%$ $\mathrm{RH}$, but halite particles aggregated with other soluble phases decrease the deliquescent point at slightly lower than $74 \%$ RH [48]. At higher humidity, such as in Cape Vilán (85 $\pm 4 \%$ ) (Table 3), these particles will deliquesce to form droplets. If several droplets were located in the glass, they could join together covering homogeneously the glass surface due to the high wettability of the glasses (Table 5).

\subsection{Influence of the exposure period}

The glasses exposed in Cape Vilán (Galicia, Spain) showed a progressive alteration related to the exposure period (Section 3.1 and 3.3) [3]. The intermittent rain in the corrosion stations induced successive cycles of wetting and drying (Table 3). After the rain, the water on the glass 
surface induced the hydroxylic attack and the dealkalization process (Reactions 1 and 2). The leached ions could also react with the atmospheric gases dissolved in the hydration water to form deposits. However, the following rainy episode would wash the glass surface removing the deposits and leached ions, and leaving new fresh water on the glass surface.

After the successive cycles, pathologies such as pits or hydration layers were formed on the glasses (Section 3.1 and 3.3). The damage produced by these pathologies is permanent even after being washed with the rain $[3,5,7,11]$. This damage can also accelerate the degradation reaction because pits can retain water favoring the formation of alteration layers around them (Figs. 3 a, b and c) [47], and the silica gel layers also retain water and leached ions, which can induce the basic mechanism of corrosion (Section 4.1) [42, 49].

\subsection{Influence of the glass composition}

Glasses presented a different behavior to the exposure depending on their chemical composition. Potash-lime silicate glass was the most altered glass, instead of soda-lime silicate and mixed-alkali silicate glasses which were "almost" stable glasses (Figs. 9 a, b and c).
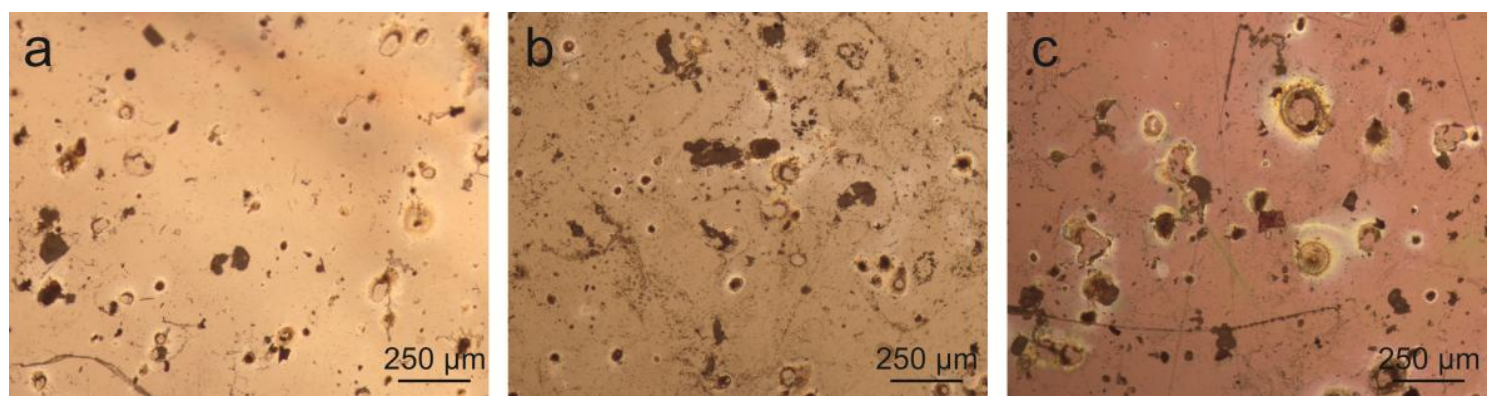

Fig. 9. OM images of the glass samples a) NCV3, b) MCV3, and c) KCV3, after 9 months of exposure.

Soda-lime silicate and mixed-alkali silicate glasses presented several deposits on the surface (Figs. 1, 9 a and 9 b). Their presence was related with both atmospheric aerosols (marine and soil particles transported by wind) and neocrystallizations formed between the leached ions from the glass and the atmospheric gases solubilized in the surface water (Section 4.1). The number of surface deposits depended on the environment more than on the chemical composition of the glass. As result of the exposure, these glasses showed a thin alteration layer in the most harmful environment and isolated pits in the samples located at more distance to the shore. The alteration in these glasses is mainly produced by surface soiling [2], deposits retain water on the glass surface inducing punctual attacks (isolated pits) [2]. Moreover, previous works $[21,50,51]$ showed that soda-lime silicates present a slow and long hydration process in aqueous media, which could be even slower in atmospheric environments. 
On the contrary, potash-lime silicate glasses formed surface alteration layers in all the samples, independently of their exposure location (Figs. $8 \mathrm{a}, \mathrm{b}$ and c). These alteration layers presented different thickness depending on the degree of alteration. This alteration layer is formed by the dealkalization of the glass network (Reaction 2) followed by a condensation reaction (Reaction 1) [1, 52]. For this reason, the increase of the intensity of the FTIR-ATR bands attributed to the bridging bonds of the silica (asymmetric stretching bands of $\mathrm{SiO}_{2}, \mathrm{U}_{\text {as }} \mathrm{Si-O-si}$ ) followed by the relative decrease of the band attributed to the non-bridging bonds (asymmetric stretching bands of $\mathrm{SiO}^{-}, \mathrm{U}_{\text {as si-o-) }}$ ) pointed to the formation of a thick surface alteration layer [53]. Higher is the relation between the bands, thicker is the alteration layer. It was observed that the formation of a thick alteration layer was faster in the Corrosion Station 2, instead of the Corrosion Station 1 (Fig. 8 a and b). This is because the alteration layer in the samples exposed near to the coast (KCV1) could be lost due to environmental conditions. On the contrary, the formation of alteration layers on the samples exposed in the Corrosion Station 3 presented the slowest process.

Potash-lime silicate glasses are more susceptible to alteration because the ionic radius of $\mathrm{K}^{+}-$ ions $(0.133 \mathrm{~nm})$ is higher than $\mathrm{Na}^{+}$-ions $(0.097 \mathrm{~nm})$ [54], which departure forms a more open structure in comparison with soda-lime silicate glasses. Regarding the chemical stability, the bond strength of groups $[\equiv \mathrm{Si}-\mathrm{O}-\mathrm{K}]$ is lower than groups $[\equiv \mathrm{Si}-\mathrm{O}-\mathrm{Na}]$ which favors the hydrolytic attack of the former bonds. Rainwater and environmental humidity are the most important factors for glass degradation in potash-lime silicate glasses and produce alteration layers $[2,3$, 42]. The evolution of the alteration layer in the samples from the Corrosion stations 1 and 2 is similar and faster than the evolution of samples from the Corrosion station 3 (Figs. 8 a, b and c). This different alteration rate was not due to the meteorology but to the content of marine aerosols (Section 4.4). In mixed-alkali silicate glasses, the moderate content of sodium ions closed the structure around the potassium ions which increased its chemical stability.

The surface topography also affects to the glass corrosion because the irregularities inherent to the artisanal blown glass retained the water in some areas (Section 3.2.), which favored its faster alteration (Fig. 2 b).

\subsection{Influence of the distance to the coast}

The glasses exposed in Cape Vilán (Galicia, Spain) showed a different behavior in function of the distance from the corrosion station to the Atlantic coast. In general, the samples exposed in the Corrosion station 1 and 2, the nearest to the shore, presented alteration layers (Figs. 10 a and b); while those samples from the Corrosion station 3 showed isolated pits (Fig. $10 \mathrm{c}$ ). 

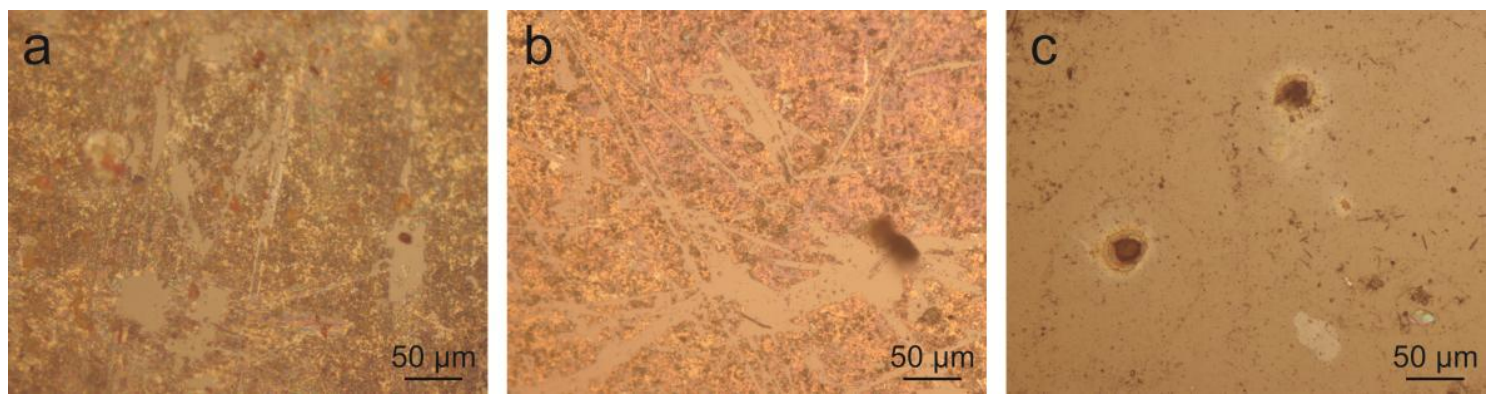

Fig. 10. OM images of the glass samples a) MCV1, b) MCV2, and c) MCV3, after 9 months of exposure. The scratching marks are due to sample manipulation.

The glasses presented the same chemical composition and they were exposed to the same atmospheric environment, so this different behavior is related to the atmospheric concentration of marine aerosols in each corrosion station (Table 2 and 3).

The coarse particles from marine aerosols are mainly composed by sea salt, predominantly sodium and chlorine ions $[39,40]$. They can form $\mathrm{NaCl}$ crystals on the glass surface, as it was observed on the surface of the samples from the Corrosion station 1 (Fig. 1 a). $\mathrm{NaCl}$ aerosols deliquesce at environmental humidity to form droplets of saline solutions (Section 4.1). The samples exposed in areas with a higher deposition rate of atmospheric chloride ions, such as Corrosion station 1 and 2 (Table 2), could be "homogeneously" covered with a layer of saline solution favoring the alteration of the entire surface at the same time. On the contrary, the glasses in the Corrosion station 3, with a lower deposition rate of atmospheric chloride ions (Table 2), presented punctual attacks (pits). This latter pathology has been previously observed as result of accelerated tests in alteration chambers without the influence of marine aerosols [55] and they are the result of surface soiling because surface deposits retained water on the glass producing punctual attacks $[10,47,55]$.

The influence of marine aerosols was also observed in the evolution of potash-lime silicate glass. The thickness of the alteration layer on the samples from the Corrosion station 3 increased slowly in comparison to the samples from the Corrosion station 1 and 2 (Figs. 8 a, b and c), showing that the high content of marine aerosols accelerated the alteration mechanism.

Previous studies $[50,51,56]$ have shown that high content of $\mathrm{Na}^{+}$-ions in an aqueous medium increase the alteration rate of silicate glasses because they can be interchanged with the $\mathrm{H}^{+}$ions from the silanols groups $[\equiv \mathrm{Si}-\mathrm{O}-\mathrm{H}]$. As consequence of the ionic exchange and the steric hindrance of the $\mathrm{Na}^{+}$-ions, [=Si-O-Na] groups were situated perpendicularly to the surface, favoring the opening of the structure and accelerating the corrosion mechanism [50]. The 
results of this study are in accordance with the mechanism proposed because, for the same time of exposure, those samples located near to the shore presented an advance state of alteration in contrast to those ones located far (Section 3.3). The high content of marine aerosols could be partially washed away by the rainwater; nevertheless, it is clear that they can modify the surface during the dry period (Table 5).

\section{Conclusions}

Glass alteration depended on both the content of marine aerosols (distance to the coast) and the chemical composition of the glasses. Those samples exposed in the corrosion stations nearest to the shore presented alteration layers, while those ones located farthest from the coast showed several isolated pits. The higher content of marine aerosols could increase the hygroscopicity of the glass surface and, also, open the glass structure favoring the alteration. While the samples exposed far from the shore showed the isolated pits related to the soiling.

Regarding the chemical composition of the glass, mixed-alkali silicate glass showed a similar behavior to soda-lime silicate glass since sodium ions closed the glass network around the potassium ions avoiding the hydrolytic attack. Nevertheless, potash-lime silicate glass was the most altered glass because its open lattice favors the hydrolytic attack.

This study proves that the stained-glass windows or glass façades located in areas with high concentration of marine aerosols, such as a few hundred meters from the coast or in areas where the wind transports a high content of sea/ocean aerosols, are threatened because the glasses in this environment can experiment a very fast alteration, even higher than in polluted environments.

\section{Acknowledgments}

The authors thank Dr. R. Wiley (FCT-UNL, Portugal) for preparing the glass roundel, Dr. L. Cerqueira (C2TN-IST/UL, Portugal) for analyzing the glass composition, Dr. M. Silva (FCT-UNL, Portugal) for his help with the interpretation of FTIR, M.C. Vázquez and B. Gallardo (IGEO, CSIC-UCM, Spain) for analyzing the angle contact of the glasses, ENEL and Gas Natural for the facilities provided at Cape Vilán wind farm for the setting up of corrosion stations, and AEMET OpenData for the meteorological information. This work has been partially funded by the Fundação do Ministério de Ciência e Tecnologia de Portugal (Project ref. UID/EAT/00729/2013 and Post-doctoral grant ref. SFRH/BPD/108403/2015) and the Community of Madrid (Research program GEOMATERIALES 2-CM Program Ref. S2013/MIT-2914). 


\section{Bibliography}

[1] M. Vilarigues, R.C. da Silva, Characterization of potash-glass corrosion in aqueous solution by ion beam and IR spectroscopy, J. Non-Cryst. Solids, 352 (2006) 5368-5375. http://dx.doi.org/10.1016/j.jnoncrysol.2006.08.032

[2] L. Gentaz, T. Lombardo, C. Loisel, A. Chabas, M. Vallotto, Early stage of weathering of medieval-like potash-lime model glass: evaluation of key factors, Environ. Sci. Pollut. R., 18 (2011) 291-300. https://doi.org/10.1007/s11356-010-0370-7

[3] M. Melcher, M. Schreiner, Evaluation procedure for leaching studies on naturally weathered potash-lime-silica glasses with medieval composition by scanning electron microscopy, J. Non-Cryst. Solids, 351 (2005) 1210-1225. https://doi.org/10.1016/i.jnoncrysol.2005.02.020

[4] M. Melcher, M. Schreiner, Leaching studies on naturally weathered potash-lime-silica $\begin{array}{llllll}\text { glasses, J. } \quad \text { Non-Cryst. } & \text { Solids, } & 352 & \text { (2006) }\end{array}$ https://doi.org/10.1016/i.jnoncrysol.2006.01.017

[5] G. Woisetschläger, M. Dutz, S. Paul, M. Schreiner, Weathering phenomena on naturally weathered potash-lime-silica-glass with Medieval composition studied by Secondary Electron Microscopy and Energy Dispersive Microanalysis, Microchim. Acta, 135 (2000) 121-130. https://doi.org/10.1007/s006040070001

[6] T. Palomar, Chemical composition and alteration processes of glasses from the Cathedral of León (Spain), Bol. Soc. Esp. Ceram. V., $57 \quad$ (2018) 101-111. https://doi.org/10.1016/j.bsecv.2017.10.001

[7] T. Lombardo, A. Chabas, R.A. Lefèvre, A. lonescu, Modelling the soiling of float glass in a polluted atmosphere, Glass Technol., 46 (2005) 192-196.

[8] O. Favez, H. Cachier, A. Chabas, P. Ausset, R. Lefevre, Crossed optical and chemical evaluations of modern glass soiling in various European urban environments, Atmos. Environ., 40 (2006) 7192-7204. https://doi.org/10.1016/i.atmosenv.2006.06.022

[9] T. Lombardo, R.A. Lefèvre, A. Chabas, P. Ausset, H. Cachier, A. Ionescu, Characterisation of particulate matter deposition inducing soiling of modern glass, in: C. Saiz-Jimenez (Ed.) CRC Press, London, 2004, pp. 209-214.

[10] M. Melcher, M. Schreiner, K. Kreislova, Artificial weathering of model glasses with medieval compositions- an empirical study on the influence of particulates, Phys. Chem. Glasses, 49 (2008) 346-356.

[11] I. Munier, R. Lefèvre, F. Geotti-Bianchini, M. Verità, Influence of polluted urban atmosphere on the weathering of low durability glasses, Glass Technol., 43 (2002) 225-237.

[12] T. Lombardo, A. Chabas, A. Verney-Carron, H. Cachier, S. Triquet, S. Darchy, Physicochemical characterisation of glass soiling in rural, urban and industrial environments, Environ. Sci. Pollut. R., 21 (2014) 9251-9258. https://doi.org/10.1007/s11356-014-2853-4

[13] C. Cardell, F. Delalieux, K. Roumpopoulos, A. Moropoulou, F. Auger, R. Van Grieken, Saltinduced decay in calcareous stone monuments and buildings in a marine environment in SW France, Constr. Build. Mater., 17 (2003) 165-179. http://dx.doi.org/10.1016/S09500618(02)00104-6

[14] I. Ozga, N. Ghedini, C. Giosuè, C. Sabbioni, F. Tittarelli, A. Bonazza, Assessment of air pollutant sources in the deposit on monuments by multivariate analysis, Sci. Total Environ., 490 (2014) 776-784. https://doi.org/10.1016/j.scitotenv.2014.05.084

[15] J. Aramendia, L. Gomez-Nubla, I. Arrizabalaga, N. Prieto-Taboada, K. Castro, J.M. Madariaga, Multianalytical approach to study the dissolution process of weathering steel: The role of urban pollution, Corros. Sci., 76 (2013) 154-162. https://doi.org/10.1016/j.corsci.2013.06.038 
[16] K. Zoghlami, P. Lopez-Arce, A. Zornoza-Indart, Differential stone decay of the Spanish tower façade in Bizerte, Tunisia, J. Mater. Civil Eng., 29 (2017) 05016005. https://doi.org/10.1061/(ASCE)MT.1943-5533.0001774

[17] M. Veneranda, J. Aramendia, O. Gomez, S. Fdez-Ortiz de Vallejuelo, L. Garcia, I. Garcia-Camino, K. Castro, A. Azkarate, J.M. Madariaga, Characterization of archaeometallurgical artefacts by means of portable Raman systems: corrosion mechanisms influenced by marine aerosol, J. Raman Spectrosc., 48 (2017) 258-266. https://doi.org/10.1002/jrs.4997

[18] N.A. Stefanis, P. Theoulakis, C. Pilinis, Dry deposition effect of marine aerosol to the building stone of the medieval city of Rhodes, Greece, Build. Environ., 44 (2009) 260-270. http://dx.doi.org/10.1016/j.buildenv.2008.03.001

[19] J. Martínez-Martínez, D. Benavente, S. Jiménez Gutiérrez, M.A. García-del-Cura, S. Ordóñez, Stone weathering under Mediterranean semiarid climate in the fortress of Nueva Tabarca island (Spain), Build. Environ., $121 \quad$ (2017) 262-276. https://doi.org/10.1016/j.buildenv.2017.05.034

[20] ICP Materials. International Co-operative Programme on Effects on Materials including Historic and Cultural Monuments [Online]. Available: http://www.corr-institute.se/icpmaterials/web/page.aspx?sid=3293 [Accessed 11/04/2018].

[21] T. Palomar, A. Chabas, D.M. Bastidas, D. de la Fuente, A. Verney-Carron, Effect of marine aerosols on the alteration of silicate glasses, J. Non-Cryst. Solids, 471 (2017) 328-337. https://doi.org/10.1016/j.jnoncrysol.2017.06.013

[22] J. Moreda-Piñeiro, E. Alonso-Rodríguez, I. Turnes-Carou, C. Moscoso-Pérez, G. BlancoHeras, L.G. Tellado, P. López-Mahía, S. Muniategui-Lorenzo, D. Prada-Rodríguez, Inorganic ions and trace metals bulk deposition at an Atlantic Coastal European region, J. Atmos. Chem., 74 (2017) 1-21. http://doi.org/10.1007/s10874-016-9338-4

[23] B. Silva, T. Rivas, E. García-Rodeja, B. Prieto, Distribution of ions of marine origin in Galicia (NW Spain) as a function of distance from the sea, Atmos. Environ., 41 (2007) 4396-4407. https://doi.org/10.1016/i.atmosenv.2007.01.045

[24] D. Dungworth, The value of historic window glass, Hist. Environ. Policy, 2 (2011) 21-48. http://doi.org/10.1179/175675011X12943261434567

[25] ISO 9225:2012, Corrosion of metals and alloys. Corrosivity of atmospheres. Measurement of environmental parameters affecting corrosivity of atmospheres, 2012.

[26] M. Morcillo, J. Alcántara, I. Díaz, B. Chico, J. Simancas, D. de la Fuente, Marine atmospheric corrosion of carbon steels, Rev. Metal., 51 (2015) e045 (041-018). http://doi.org/10.3390/ma10040406

[27] ISO 4287:1997, Geometrical Product Specifications (GPS). Surface texture: Profile method. Terms, definitions and surface texture parameters, 1997.

[28] UNE-EN 15802:2010, Conservation of cultural property. Test methods. Determination of static contact angle 2010.

[29] J.E. Ritter, P. Strzepa, K. Jakus, L. Rosenfeld, K.J. Buckman, Erosion damage in glass and alumina, J. Am. Ceram. Soc., 67 (1984) 769-774. https://doi.org/10.1111/j.11512916.1984.tb19515.x

[30] B. Barka, A. Faci, N. Bouaouadja, C. Bousbaa, D. Benachour, M. Fatmi, Influence of the velocity and impact angle on the distribution of the surface defects of a sandblasted glass, Int. J. Appl. Glass Sci., (2018). https://doi.org/10.1111/ijag.12349

[31] M. Hilker, T. Meiners, Chemoecology of insect eggs and egg deposition, Wiley-Blackwell, Berlin, Germany, 2008.

[32] A. Rodrigues, S. Fearn, M. Vilarigues, Glass deterioration in the Museum environment: a case study in Lisbon Portugal, in: I. Biron, F. Alloteau, O. Majérus, P. Lehuédé, D. Caurant (Eds.) Proceedings of the International Symposium on Glass Degradation in Atmospheric Conditions, Hermann Editions, Paris, 2018. 
[33] F.M. Ernsberger, Properties of glass surfaces, Annu. Rev. Mater. Sci., 2 (1972) 529-572. http://doi.org/10.1146/annurev.ms.02.080172.002525

[34] R.M. Almeida, C.G. Pantano, Structural investigation of silica gel films by infrared spectroscopy, J. Appl. Phys., 68 (1990) 4225-4232. http://doi.org/10.1063/1.346213

[35] M.C. Peel, B.L. Finlayson, T.A. McMahon, Updated world map of the Köppen-Geiger climate classification, Hydrol. Earth Syst. Sci., 11 (2007) 1633-1644. http://doi.org/10.5194/hess-11-1633-2007

[36] Iberian climate atlas. Air temperature and precipitation (1971-2000), Agencia Estatal de Meteorología, Instituto de Meteorologia de Portugal, Unidad de Documentación de AEMET, 2011.

[37] I.F. Tullot, Climatología de España y Portugal, Ediciones Universidad de Salamanca, Salamanca, 2000.

[38] M. Kottek, J. Grieser, C. Beck, B. Rudolf, F. Rubel, World Map of the Köppen-Geiger climate classification updated, Meteorol. Z., 15 (2006) 259-263. https://doi.org/10.1127/09412948/2006/0130

[39] J.W. Fitzgerald, Marine aerosols: A review, Atmos. Environ., 25 (1991) 533-545. https://doi.org/10.1016/0960-1686(91)90050-H

[40] J. Heintzenberg, D.C. Covert, R.V. Dingenen, Size distribution and chemical composition of marine aerosols: a compilation and review, Tellus B, 52 (2000) 1104-1122. http://doi.org/10.3402/tellusb.v52i4.17090

[41] D.B. Asay, S.H. Kim, Evolution of the adsorbed water layer structure on silicon oxide at room temperature, J. Phys. Chem. B, 109 (2005) 16760-16763. http://doi.org/10.1021/jp0530420

[42] L. Gentaz, T. Lombardo, A. Chabas, C. Loisel, D. Neff, A. Verney-Carron, Role of secondary phases in the scaling of stained glass windows exposed to rain, Corros. Sci., 109 (2016) 206216. https://doi.org/10.1016/j.corsci.2016.04.005

[43] W.A. Lanford, K. Davis, P. Lamarche, T. Laursen, R. Groleau, R.H. Doremus, Hydration of soda-lime glass, J. Non-Cryst. Solids, 33 (1979) 249-266. https://doi.org/10.1016/00223093(79)90053-X

[44] B.C. Bunker, Molecular mechanisms for corrosion of silica and silicate glasses, J. Non-Cryst. Solids, 179 (1994) 300-308. https://doi.org/10.1016/0022-3093(94)90708-0

[45] T.M. El-Shamy, J. Lewins, R.W. Douglas, The dependence on the $\mathrm{pH}$ of the decomposition of glasses by aqueous solutions, Glass Technol., 13 (1972) 81-87.

[46] E. Greiner-Wronowa, L. Stoch, Influence of environment on surface of the ancient glasses, J. Non-Cryst. Solids, 196 (1996) 118-127. http://dx.doi.org/10.1016/0022-3093(95)00563-3

[47] S. Reiß, R. Grieseler, S. Krischok, E. Rädlein, The influence of Sahara sand on the degradation behavior of float glass surfaces, J. Non-Cryst. Solids, 479 (2018) 16-28. https://doi.org/10.1016/i.jnoncrysol.2017.09.055

[48] M.E. Wise, T.A. Semeniuk, R. Bruintjes, S.T. Martin, L.M. Russell, P.R. Buseck, Hygroscopic behavior of $\mathrm{NaCl}$-bearing natural aerosol particles using environmental transmission electron microscopy, J. Geophys. Res. - Atmos., 112 (2007) D10224 (00001-00012). https://doi.org/10.1029/2006JD007678

[49] T. Palomar, Effect of soil pH on the degradation of silicate glasses, Int. J. Appl. Glass Sci., 8 (2017) 177-187. http://doi.org/10.1111/ijag.12226

[50] P.M. Dove, S.F. Elston, Dissolution kinetics of quartz in sodium chloride solutions: Analysis of existing data and a rate model for $25^{\circ} \mathrm{C}$, Geochim. Cosmochim. Ac., 56 (1992) 4147-4156. https://doi.org/10.1016/0016-7037(92)90257-J

[51] T. Palomar, I. Llorente, Decay processes of silicate glasses in river and marine aquatic $\begin{array}{llllll}\text { environments, J. } & \text { Non-Cryst. Solids, } 449 & \text { (2016) }\end{array}$ https://doi.org/10.1016/j.jnoncrysol.2016.07.009 
[52] M.E. Lynch, D.C. Folz, D.E. Clark, Use of FTIR reflectance spectroscopy to monitor corrosion mechanisms on glass surfaces, J. Non-Cryst. Solids, 353 (2007) 2667-2674. http://dx.doi.org/10.1016/i.jnoncrysol.2007.05.012

[53] F. Geotti-Bianchini, C. Nicola, M. Preo, M. Vallotto, M. Verità, MicrolRRS and EPMA study of the weathering of potash-lime-silicate glasses, Rivista della stazione sperimentale del vetro, 35 (2005) 49-61.

[54] F. Burriel Martí, F. Lucena Conde, S. Arribas Jimeno, J. Hernández Méndez, Química analítica cualitativa, $18^{\text {th }}$ edition, Thomson, Madrid, 2002.

[55] T. Palomar, La interacción de los vidrios históricos con medios atmosféricos, acuáticos y enterramientos. PhD dissertation, Universidad Aunónoma de Madrid (Spain), 2013.

[56] N. Carmona, M. García-Heras, C. Gil, M.A. Villegas, Chemical degradation of glasses under simulated marine medium, Mater. Chem. Phys., 94 (2005) 92-102. https://doi.org/10.1016/j.matchemphys.2005.04.026 